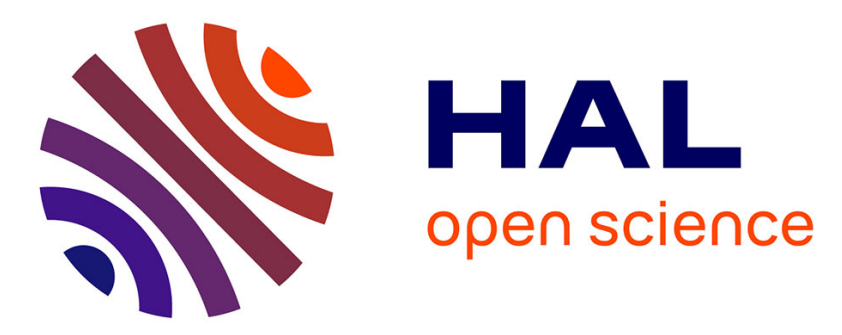

\title{
A split Hopkinson pressure bar device to carry out confined friction tests under high pressures
}

Bastien Durand, Franck Delvare, Patrice Bailly, Didier Picart

\section{To cite this version:}

Bastien Durand, Franck Delvare, Patrice Bailly, Didier Picart. A split Hopkinson pressure bar device to carry out confined friction tests under high pressures. International Journal of Impact Engineering, 2016, 88, pp.54 - 60. 10.1016/j.ijimpeng.2015.09.002 . hal-01564488

\section{HAL Id: hal-01564488 \\ https://hal.science/hal-01564488}

Submitted on 19 Jul 2017

HAL is a multi-disciplinary open access archive for the deposit and dissemination of scientific research documents, whether they are published or not. The documents may come from teaching and research institutions in France or abroad, or from public or private research centers.
L'archive ouverte pluridisciplinaire HAL, est destinée au dépôt et à la diffusion de documents scientifiques de niveau recherche, publiés ou non, émanant des établissements d'enseignement et de recherche français ou étrangers, des laboratoires publics ou privés. 


\section{A SPLIT HOPKINSON PRESSURE BAR DEVICE TO CARRY OUT CONFINED} FRICTION TESTS UNDER HIGH PRESSURES

${ }^{1}$ LMT, ENS-Cachan, 94235 CACHAN Cedex, France, bastien.durand@lmt.ens-cachan.fr, $+33147402193$

${ }^{2}$ Université de Caen, Normandie, Laboratoire N. Oresme, F-14032 Caen, France

${ }^{3}$ INSA CVL, Laboratoire PRISME, F-18020 Bourges, France

${ }^{4}$ CEA, DAM, Le Ripault, F-37260 Monts, France

Abstract: Numerical simulations of mechanical loadings on pyrotechnic structures require the determination of the friction coefficient between steel and explosives. Our study focuses on contact pressures of around $100 \mathrm{MPa}$ and sliding velocities of around $10 \mathrm{~m} / \mathrm{s}$. Explosives are brittle materials which fracture when submitted to such pressures in uniaxial compression. They have therefore to be confined to avoid any fracture during the tests. A new Hopkinson bar device which simultaneously enables to confine a sample and rub it on steel has therefore been designed. This device is composed of two coaxial transmission bars. It consists in a cylindrical sample confined in a steel tube, the cylindrical sample being inserted between the incident bar and the internal transmission bar, and the confinement tube being leant against the external transmission bar. The high impedance of the external transmission bar keeps the confinement tube quasi-motionless whereas the impedance of the internal transmission bar is calculated to reach the desired pressure and the desired velocity at the tube-sample interface. Tests have been carried out with an inert material mechanically representative of explosives. The friction coefficient and the stresses at the tube-sample 
interface are deduced from strain measurements on the Hopkinson bars and on the external face of the confinement tube, and from an analytical model.

Keywords: friction parameter, identification, confinement, split Hopkinson pressure bars

\section{Introduction}

Numerical simulations are performed to predict the ignition of confined explosives submitted to accidental impacts [1], [2], [3]. Such impacts are characterised by velocities of several tens of meters per second and are usually called "low-velocity impacts". These simulations are based on:

- An elasto-plastic model simulating the macroscopic behaviour, whose parameters are identified from triaxial tests.

- A thermo-chemical model enabling the calculation of the local heat due to the irreversible macroscopic strain and due to chemical reactions.

The parameters of the thermo-chemical model are identified from normalised experimental tests supposed to reproduce accidental situations: the drop-weight test [4], the Steven-test [3], [5], [6], the Susan-test [3] and the Taylor test [7] among others. Unfortunately, numerical simulations of these normalised tests show that the ignition time of the explosive strongly depends on the friction coefficient at the interface between the explosive and the contact materials (generally steel). A test enabling the friction coefficient measurement between steel and explosives under the "low-velocity impacts" conditions has therefore to be designed.

Numerical simulations display that the "low-velocity impacts" lead to contact pressures reaching $100 \mathrm{MPa}$ and sliding velocities reaching $10 \mathrm{~m} / \mathrm{s}$ at the interfaces. Few 
tribometers satisfy these requirements: tribometer with explosively-driven friction [8], targetprojectile assembly with oblique impact [9], Hopkinson torsion bars [10], dynamometrical ring with parallelepipedic specimen launched by a gas gun or an hydraulic machine [11] and the friction of a pin on a revolving disc [12], [13]. With these classical tribometers, mainly used on metals and ceramics, the friction samples are tested in simple compression and this configuration is unfortunately not adapted to our situation, as explained above.

For safety reasons, our friction tests are carried out with an inert material mechanically representative of an explosive. This material is named the I1. The I1 Young's modulus is $2 \mathrm{GPa}$, its Poisson's ratio $v$ is estimated to 0.4 and its density is $1850 \mathrm{~kg} / \mathrm{m}^{3}$ [14]. Its inelastic behavior has been studied by carrying out triaxial compression tests [14]. The material flow when its plasticity threshold has been attained (for the sake of simplicity the maximal stresses obtained using triaxial tests are used to define a plasticity threshold). The plasticity flow threshold is defined by a Drucker-Prager criterion [14]:

\section{(1) $\sigma_{\text {mis }}-\alpha P<C$}

where $P$ is the hydrostatic pressure and $\sigma_{m i s}$ the Von Mises equivalent stress.

Conventionally, the stress in the I1 is positive in compression and negative in traction. A plastic incompressibility and a perfectly plastic behavior (i.e. $C$ constant) are assumed. The parameters have been determined: $C=25 \mathrm{MPa}$ and $\alpha=0.64$ [14].

According to relation (1), in the case of a simple compression loading, the maximum axial stress is only $31 \mathrm{MPa}$. The I1 behavior is quasi-brittle, so when this limit stress is reached, it breaks. The desired $100 \mathrm{MPa}$ pressure cannot therefore be reached with classical 
tribometers because of the I1 fracture. The material has therefore to be confined during our tests for two following reasons:

- The behavior of the confined material remains elastic even under high stresses.

- A confinement situation avoids any fracture to occur when the elasticity limit is reached.

A cylindrical I1 sample is thus enclosed in a steel tube. This technique is usually employed to perform compression tests with quasi-uniaxial strain states [14], [15]. Our test bench has to be designed to enables friction to occur between the I1 sample and the steel tube. Our experimental configuration is similar to the compaction tests one [16], [17], [18].

The Hopkinson bar set-up, its potential performances and the friction identification from a test and from an analytical model are described in section 2. Then, the consistency of this identification is verified in section 3 by performing numerical finite element simulations.

\section{The Hopkinson bar set-up}

\section{$2.1 \quad$ Design and modeling}

The Hopkinson bar device used for our friction tests has two coaxial output bars (Figure 1). It consists in an I1 cylindrical sample confined in a steel tube, the sample being inserted between the incident bar (via a plug, see Figure 2) and the internal output bar, and the confinement tube being leant against the external output bar. The high impedance of the external output bar keeps the confinement tube quasi-motionless whereas the impedance of the internal output bar is calculated to reach the desired pressure and the desired velocity at the tube-sample interface. Thus, the steel tube acts both as a confinement, which avoids any 
100 fracture in the I1 sample, and as a friction surface. The radial pressure at the confinement

101 tube - sample interface is generated by the axial compression of the sample.

102

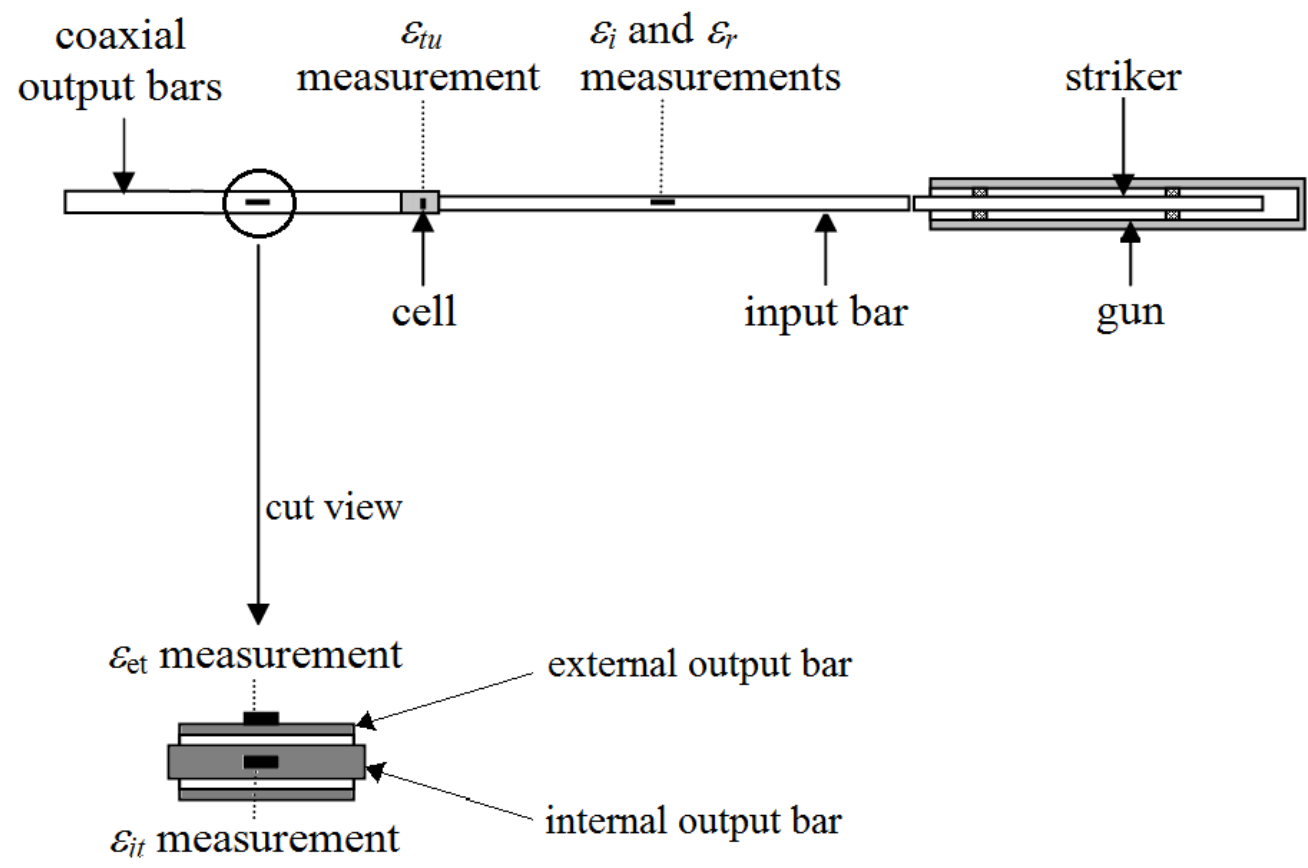

104 Figure 1: The Split Hopkinson Pressure Bar device. $\varepsilon_{i}$ : incident strain wave, $\varepsilon_{r}$ : reflected

105 strain wave, $\varepsilon_{t u}$ : strain measured on the confinement tube, $\varepsilon_{e t}$ : external transmitted strain

106 wave, $\varepsilon_{i t}$ : internal transmitted strain wave.

107 


\begin{tabular}{|c|c|c|c|c|c|c|}
\hline \multirow{2}{*}{ bar } & \multirow{2}{*}{ material } & \multirow{2}{*}{$\begin{array}{l}\text { Young's } \\
\text { modulus }\end{array}$} & \multirow{2}{*}{ waves celerity } & \multicolumn{2}{|c|}{ diameters } & \multirow[t]{2}{*}{ length } \\
\hline & & & & external & internal & \\
\hline striker & & & & & & $1.05 \mathrm{~m}$ \\
\hline input & SLECI & $L_{l}-1000 \mathrm{a}$ & $C_{l}-4 J J J 111 / \mathrm{S}$ & $2 \Lambda_{l}-2010110$ & & $2.5 \mathrm{~m}$ \\
\hline $\begin{array}{l}\text { internal } \\
\text { output }\end{array}$ & aluminum & $E_{i o}=72.8 \mathrm{GPa}$ & $C_{i o}=5092 \mathrm{~m} / \mathrm{s}$ & $2 R_{i o}=10 \mathrm{~mm}$ & & $1.46 \mathrm{~m}$ \\
\hline $\begin{array}{l}\text { external } \\
\text { output }\end{array}$ & steel & $E_{e o}=205 \mathrm{GPa}$ & $C_{e o}=5162 \mathrm{~m} / \mathrm{s}$ & $2 R_{e e o}=40 \mathrm{~mm}$ & $2 R_{\text {ieo }}=30 \mathrm{~mm}$ & $1.5 \mathrm{~m}$ \\
\hline
\end{tabular}

108 Table 1: Young's moduli, tensile/compressive waves celerities, diameters and lengths of the 109 bars.

The impact of the striker induces an incident compressive strain wave $\varepsilon_{i}$ in the input

112 bar (Figure 1). Reverberation occurs in the cell (cell details are given on Figure 2), which

113 leads to a reflected strain wave $\varepsilon_{r}$ in the input bar, to a transmitted compressive strain wave $\varepsilon_{i t}$

114 in the internal output bar and to a transmitted compressive strain wave $\varepsilon_{e t}$ in the external

115 output bar. $\varepsilon_{i}$ and $\varepsilon_{r}$ are both measured by a longitudinal strain gauge glued on the input bar,

116 at $1.22 \mathrm{~m}$ from the plug interface, where the two waves are separated in time. $\varepsilon_{i t}$ is measured

117 by a longitudinal strain gauge glued at $330 \mathrm{~mm}$ from the sample interface and $\varepsilon_{e t}$ is measured

118 by a longitudinal strain gauge glued on the external face of the external output bar and at $119295 \mathrm{~mm}$ from the confinement tube interface. 


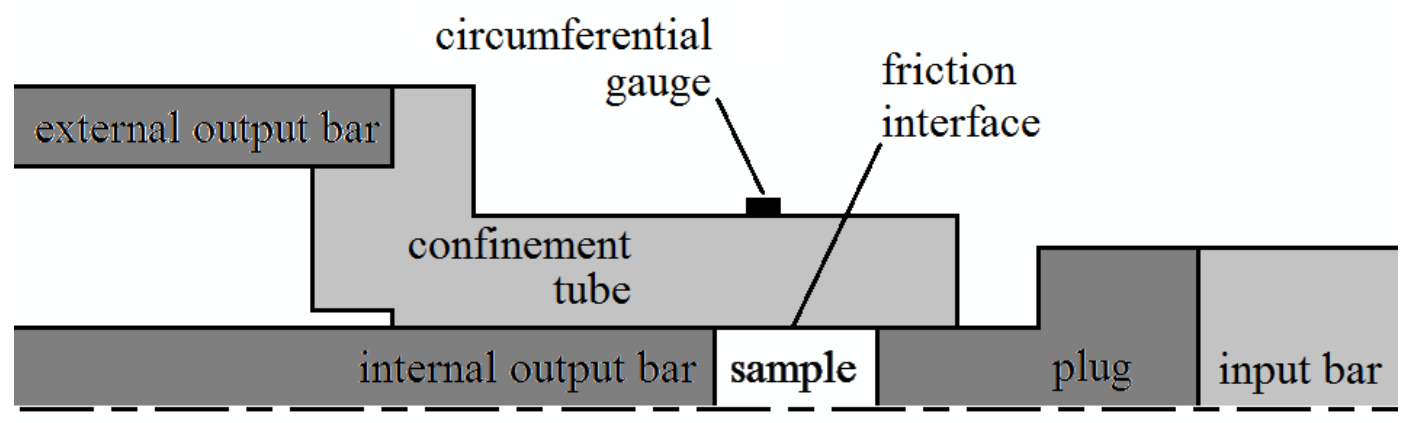

122 Figure 2: Zoom on the mounting with the cell composed of the plug, the sample and the

123 confinement tube (axisymmetric cut view).

124

125

126

127

The sample has a diameter $2 R$ and a length $L$ equal to $10 \mathrm{~mm}$, the confinement tube has an external diameter $2 R_{t}$ equal to $24 \mathrm{~mm}$ and the length scale is respected on Figure 2. The confinement tube and the plug, made of steel, have a Young's modulus $E_{t}$ and a Poisson's ratio $v_{t}$ respectively equal to $200 \mathrm{GPa}$ and to 0.29 . The friction face of the confinement tube has been reamed and the sample was turned on a sliding lathe. Both have a weak surface roughness representative of the pyrotechnic structures roughness (arithmetic average of absolute values $R_{a}$ roughly equal to 0.8 ). The radial clearance between the plug and the tube and between the internal output bar and the tube is of the order of $0.01 \mathrm{~mm}$. Teflon sheets have been inserted between the plug and the sample and between the internal output bar and the sample in order to reduce the friction at these interfaces and thus increase the pressure at the tube-sample interface. The circumferential gauge glued on the confinement tube is $2 \mathrm{~mm}$ wide. The initial axial distance between the sample middle and the gauge middle is chosen equal to $2.5 \mathrm{~mm}$ because the sample displacement relatively to the tube during the test is supposed to be around $5 \mathrm{~mm}$. Thus, the gauge is glued at the mean axial position of the sample middle. 
142 plug interface can be determined from the Hopkinson formulae (2) and from strain waves $\varepsilon_{i}$

143 and $\varepsilon_{r}$ measured by the gauge and virtually transported at the input bar - plug interface (see

144 Table 1 for symbols definitions):

145

146

(2) $\left\{\begin{array}{l}F_{i}=-\pi R_{i}^{2} E_{i}\left(\varepsilon_{i}+\varepsilon_{r}\right) \\ V_{i}=C_{i}\left(\varepsilon_{r}-\varepsilon_{i}\right)\end{array}\right.$ the internal output bar - sample interface can be determined from the Hopkinson formulae (3) and from strain wave $\varepsilon_{i t}$ measured by the gauge and virtually transported at the internal output

151 bar - sample interface:

152

$$
\text { (3) }\left\{\begin{array}{l}
F_{i o}=-\pi R_{i o}{ }^{2} E_{i o} \varepsilon_{i t} \\
V_{i o}=-C_{i o} \varepsilon_{i t}
\end{array}\right.
$$
velocity $V_{e o}$ at the external output bar - confinement tube interface can be determined from the Hopkinson formulae (4) and from strain wave $\varepsilon_{e t}$ measured by the gauge and virtually transported at the external output bar - confinement tube interface:

160

$$
\text { (4) }\left\{\begin{array}{l}
F_{e o}=\pi\left(R_{i e o}^{2}-R_{e e o}^{2}\right) E_{e o} \varepsilon_{e t} \\
V_{e o}=-C_{e o} \varepsilon_{e t}
\end{array}\right.
$$


163 gives:

164

165

(5) $\quad F_{i}=F_{e o}+F_{i o}$

166

The stationary state of the cell gives:

168

169

(6) $\quad V_{i}=V_{i o}$

170

171 In the case of a stationary state, the sliding velocity at the friction interface $V$ can be

172 expressed as following:

173

174

(7) $\quad V=V_{i o}-V_{e o} \quad$ or $\quad V=V_{i}-V_{e o}$

175

176 The sample behavior has to be modeled to obtain a second relation between the forces

$177 F_{i}, F_{e o}$ and $F_{i o}$. The model used is similar of the Janssen's one [19] and has been previously

178 used by the authors in [20] and [21]. The approach is based on three assumptions:

179 (i) the confinement tube is assumed to be perfectly rigid,

180 (ii) the sample behavior remains elastic,

181 (iii) in the sample, the axial, radial and circumferential stresses and strains do not depend on 182 the radial coordinate.

183 

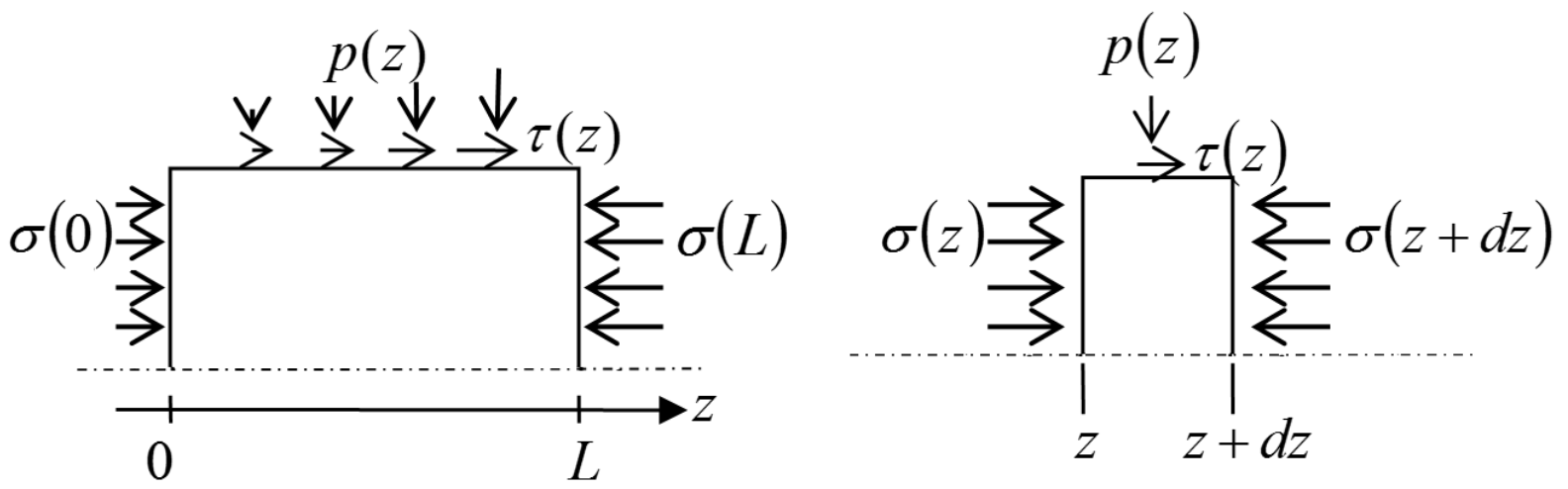

185 Figure 3: Stresses in the sample. $z$ : axial coordinate, $p(z)$ : radial pressure, $\tau(z)$ : friction stress

186 applied by the tube on the interface, $\sigma(z)$ : axial stress.

187

If the stresses in the sample (Figure 3) are positive in compression and negative in traction, the Hooke's law leads to the following relation:

190

191

(8) $\frac{p(z)}{\sigma(z)}=\frac{v}{1-v}$

$v$ being the I1 Poisson's ratio.

193

(9) $2 \tau(z)=R \sigma^{\prime}(z)=R \frac{d \sigma(z)}{d z}$

$R$ being the sample radius.

198

200 leads to:

201

$202 \quad(10) \quad \tau(z)=f p(z)$ 
The relations (8), (9) and (10) lead to a differential equation:

205

206

(11) $\frac{\sigma^{\prime}(z)}{\sigma(z)}=\frac{2 f v}{R(1-v)}$

(12) $\left\{\begin{array}{l}F_{i}=\pi R^{2} \sigma(L) \\ F_{i o}=\pi R^{2} \sigma(0)\end{array}\right.$

we obtain:

213

214

(13) $\frac{F_{i}}{F_{i o}}=\exp (\beta f)$ with $\beta=\frac{2 v L}{R(1-v)}$

(14) $\varepsilon_{i}=-\frac{V_{s}}{2 C_{i}}$

Thanks to the Hopkinson formulae (2), (3) and (4), thanks to the equilibrium state equation (5), thanks to the stationary state equation (6), and thanks to relation (13), the mean pressure along the friction interface $p_{\text {mean }}$ and the sliding velocity $V$ can be determined from

223 the impact velocity of the striker $V_{s}$, from the friction coefficient $f$ and from the set-up 224 parameters: 


$$
p_{\text {mean }}=\frac{R_{i}^{2} R_{i o}{ }^{2} E_{i} E_{i o}[\exp (\beta f)-1]}{2 f R L\left[R_{i}^{2} E_{i} C_{i o}+R_{i o}{ }^{2} E_{i o} C_{i} \exp (\beta f)\right]} V_{s}
$$

$$
V=\frac{R_{i}{ }^{2} E_{i}\left\{C_{i o}-\frac{R_{i o}{ }^{2} E_{i o} C_{e o}[\exp (\beta f)-1]}{\left(R_{e e o}{ }^{2}-R_{i e o}{ }^{2}\right) E_{e o}}\right\}}{R_{i}{ }^{2} E_{i} C_{i o}+R_{i o}{ }^{2} E_{i o} C_{i} \exp (\beta f)} V_{s}
$$

Relations (15) and (16) enable to choose the apparatus dimensions ( $L, R, R_{i}, R_{i o}, R_{e e o}$ and $\left.R_{i e o}\right)$, the apparatus materials $\left(E_{i}, C_{i}, E_{i o}, C_{i o}, E_{e o}\right.$ and $\left.C_{e o}\right)$ and the striker initial velocity $V_{s}$ knowing the sample Poisson's ratio $v$, the friction coefficient $f$ and the desired interface solicitations $\left(p_{\text {mean }}\right.$ and $V$ ). It must be highlighted that an accurate calculation of the apparatus needs to know a priori an order of the friction coefficient $f$ magnitude and needs to know accurately the sample Poisson's ratio $v$. The striker of our apparatus can be launched at $10 \mathrm{~m} / \mathrm{s}$. Figure 4 therefore displays the magnitudes of the mean pressure and of the sliding

237 velocity that can be reached with our set-up. Figure 4 shows that the mean pressure increases 238 and that the sliding velocity decreases when the friction coefficient increases. The desired $100 \mathrm{MPa}$ pressure and the desired $10 \mathrm{~m} / \mathrm{s}$ sliding velocity can almost be simultaneously approached for very low friction coefficients (lower than 0.1). It could be noted that the

241 pressure and the sliding velocity cannot be simultaneously imposed to a desired value because 242 one depends on the other. 


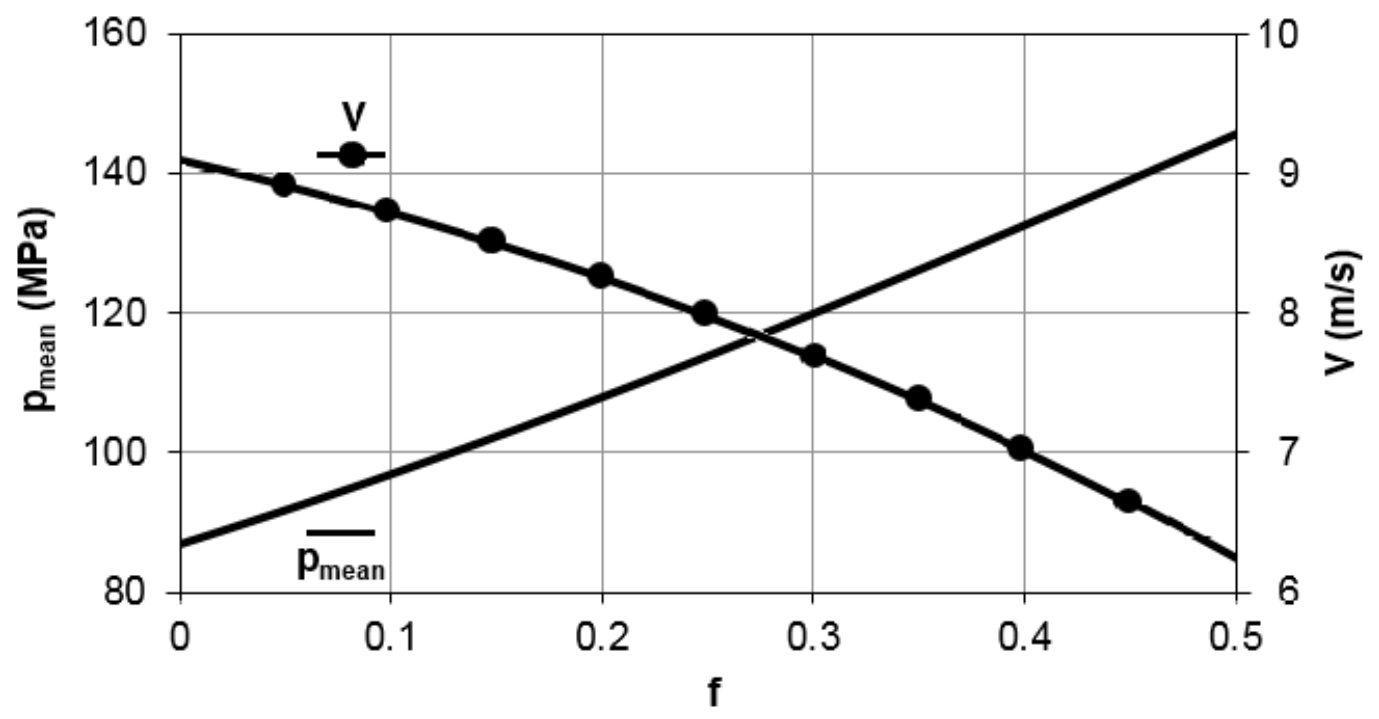

245 Figure 4 : Evolution of the mean pressure $p_{\text {mean }}$ and of the sliding velocity $V$ as a function of 246 the friction coefficient $f$.

None of the former devices enables to reach such friction solicitations. The tribometer used in [20] enables to reach a sliding velocity of around $10 \mathrm{~m} / \mathrm{s}$ but limits the mean pressure to $20 \mathrm{MPa}$ whereas the tribometer used in [21] and in [22] enables to reach a mean pressure of around $100 \mathrm{MPa}$ but limits the sliding velocity to $2 \mathrm{~m} / \mathrm{s}$.

\subsection{Analysis of measurements}

A test has been conducted to experimentally check if the sample reaches a stationary equilibrium state as assumed in section 2.1. The time evolutions of the raw strains are shown on Figure 5. The forces applied by the bars on the cell and the velocities at the bars-cell interfaces are then determined from the Hopkinson formulae (2), (3) and (4). The input force can be compared to the output force on Figure 6 and the sample input velocity can be compared to the sample output velocity on Figure 7. 


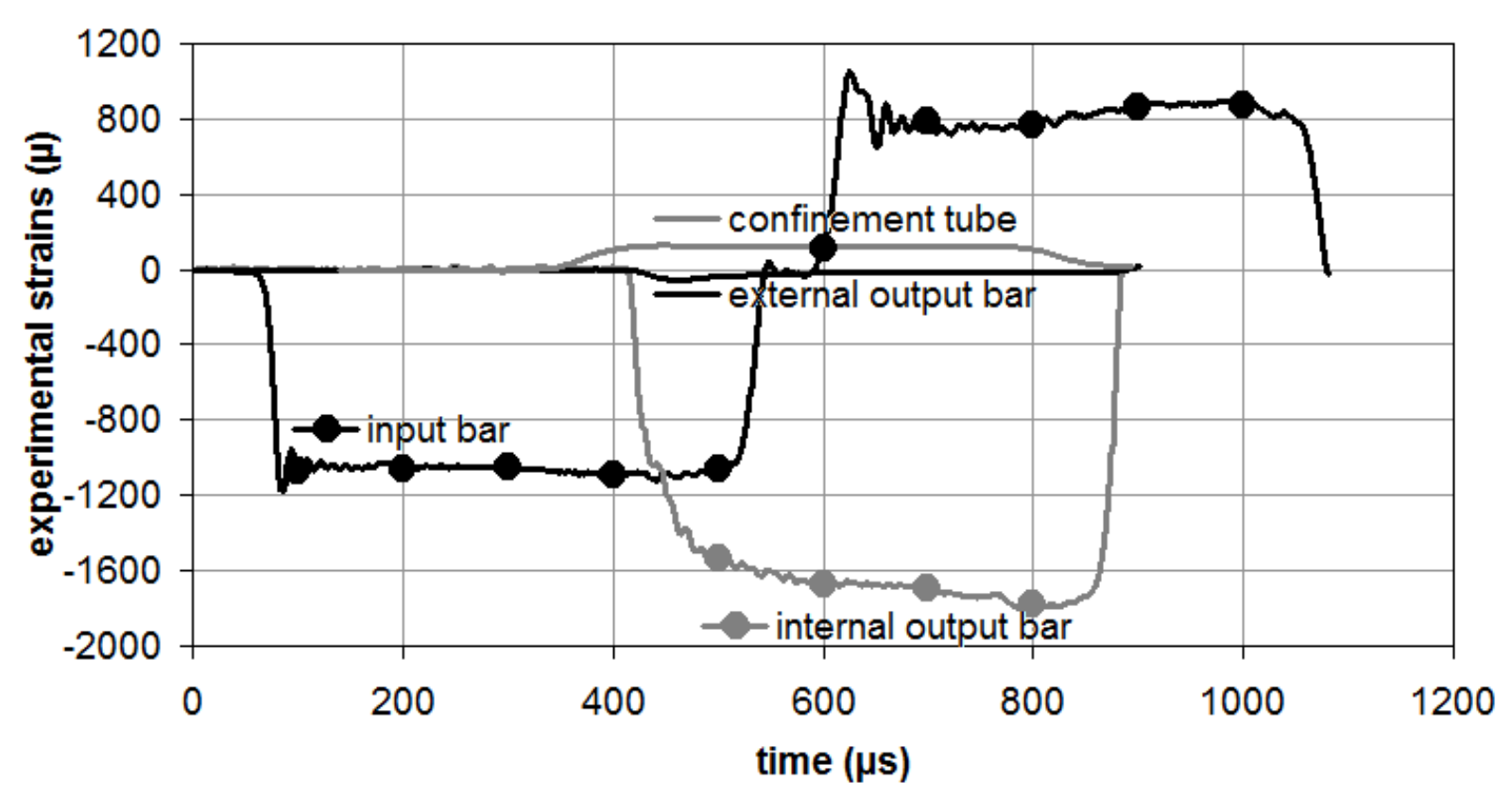

263 Figure 5: Time evolutions of the raw strains measured by the gauges glued on bars and on the 264 confinement tube. The strain measured on the external output bar is very low compared to the 265 others. on the other figures and will be no more used in the paper. 


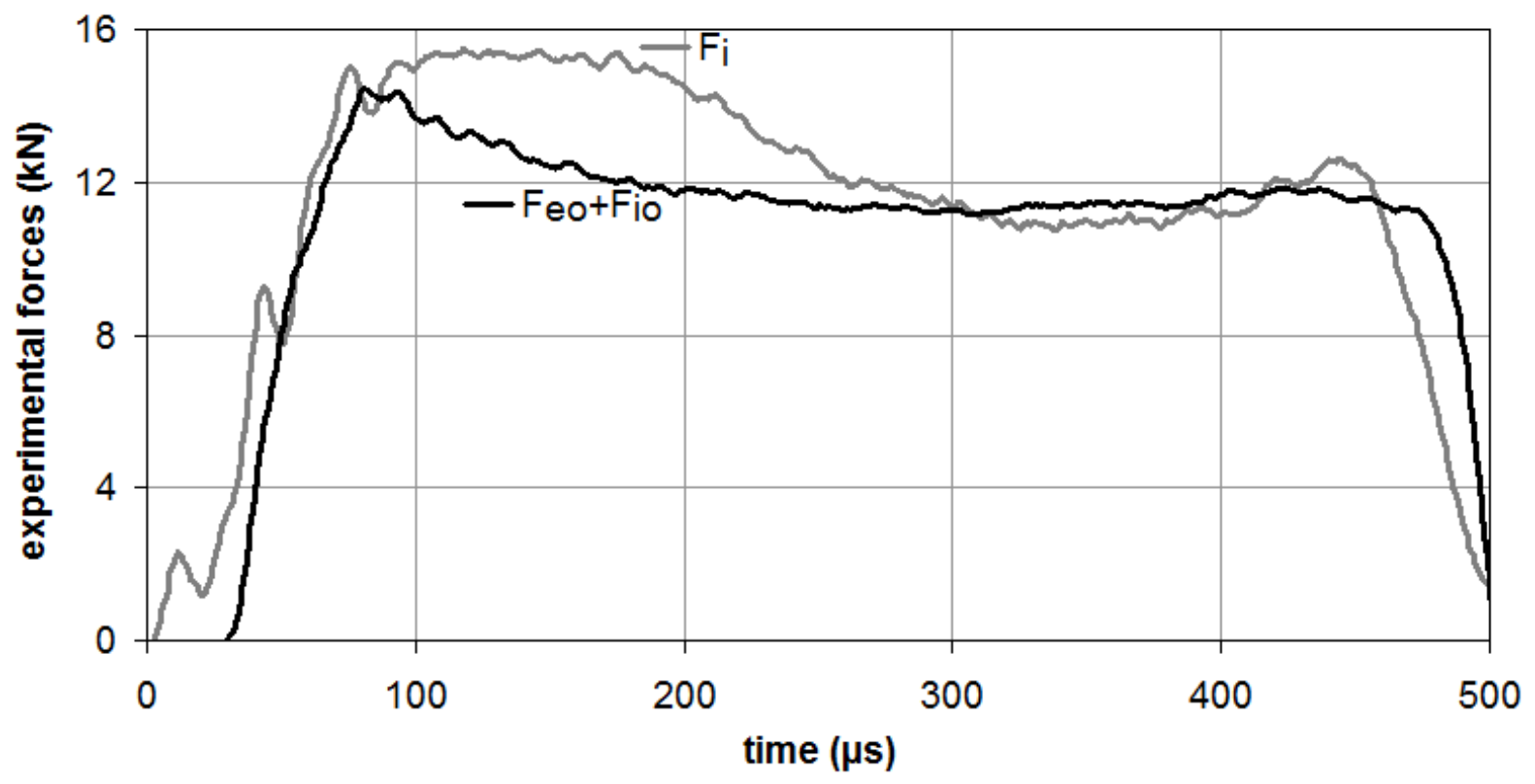

271 Figure 6: Time evolutions of the input force $F_{i}$ and of the sum of the external output force and 272 of the internal output force $F_{e o}+F_{i o}$ deduced from the measured strain waves in the bars and 273 from the Hopkinson formulae.

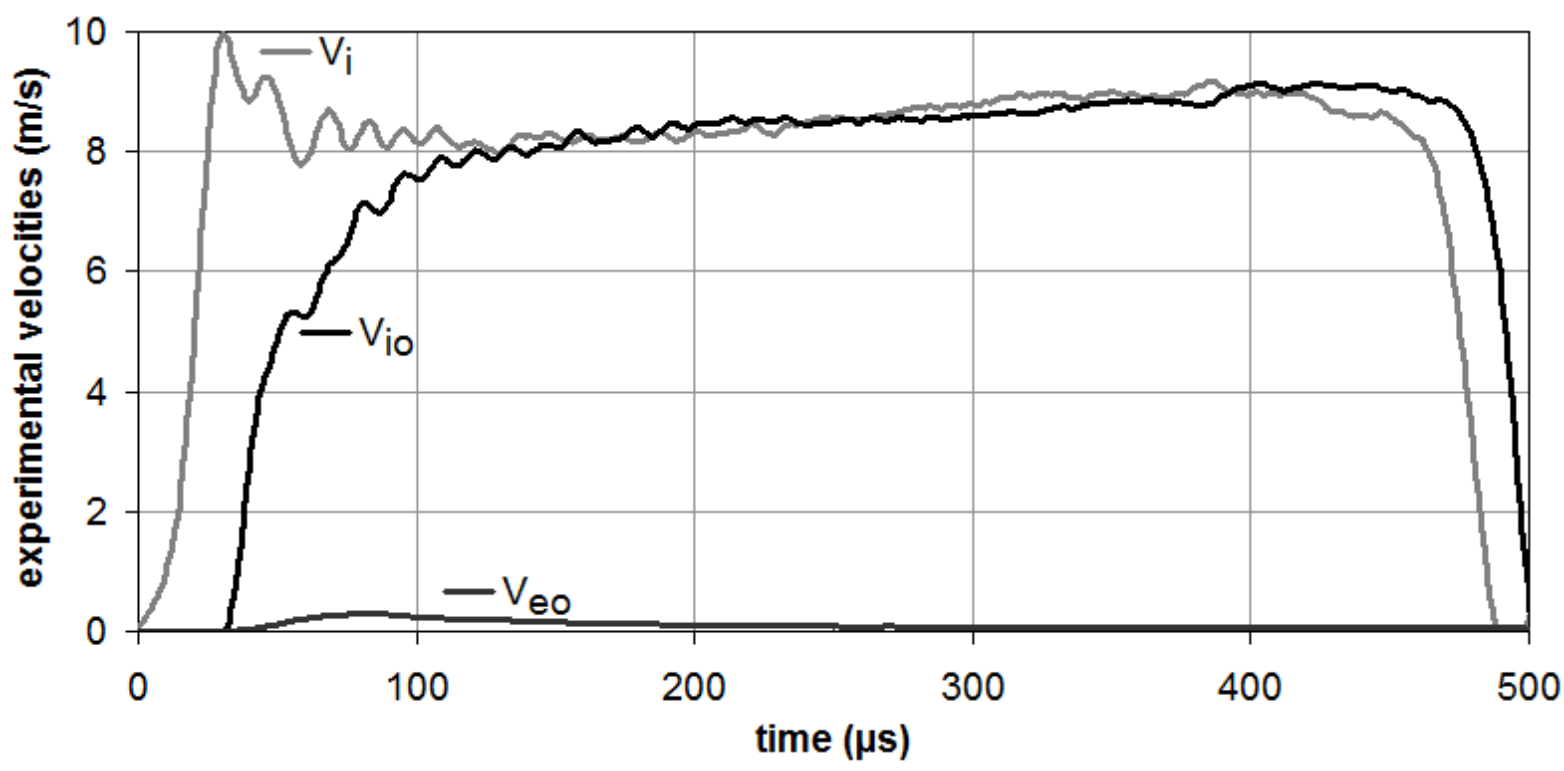

276 Figure 7: Time evolutions of the input velocity $V_{i}$, of the internal output velocity $V_{i o}$ and of

277 the external output velocity $V_{e o}$ deduced from the measured strain waves in the bars and from 278 the Hopkinson formulae. 
A quite satisfactory stationary equilibrium state can be observed on Figure 6 and

281 Figure 7 . The evolution of the experimental input force $F_{i}$ during the transient phase (at the 282 beginning) can be explained by the time shifting of the incident and the reflected waves $\varepsilon_{i}$ and $283 \varepsilon_{r}$. These two waves being quasi-opposed (Figure 8), uncertainties are amplified when the 284 input force is calculated with formula (2). The experimental evolution of $F_{i}$ will therefore not 285 be used to identify the friction coefficient $f$ and we will focus only on the stationary phase 286 (approximately from $300 \mu \mathrm{s}$ to $400 \mu \mathrm{s}$ ).

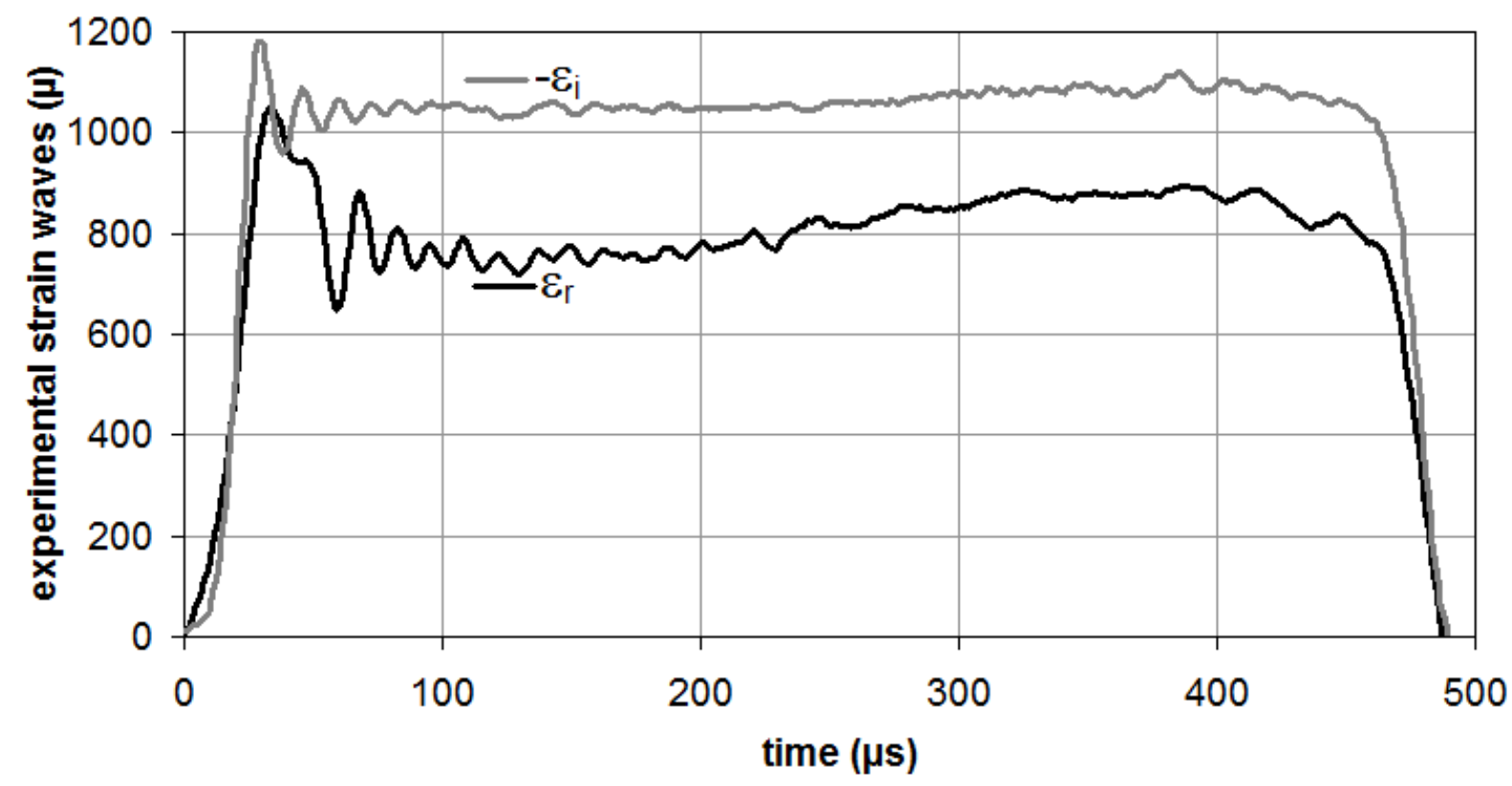

Figure 8: Time evolutions of the opposite of the measured incident strain wave $\varepsilon_{i}$ and of the 290 measured reflected wave $\varepsilon_{r}$, both virtually transported at the input bar - plug interface.

Figure 7 shows that the sliding velocity $V$ is of the order of $8-9 \mathrm{~m} / \mathrm{s}$ during the stationary phase. 
296 output forces ratio $\frac{F_{e o}}{F_{i o}}$ :

$$
f=\frac{\ln \left(\frac{F_{e o}}{F_{i o}}+1\right)}{\beta}
$$

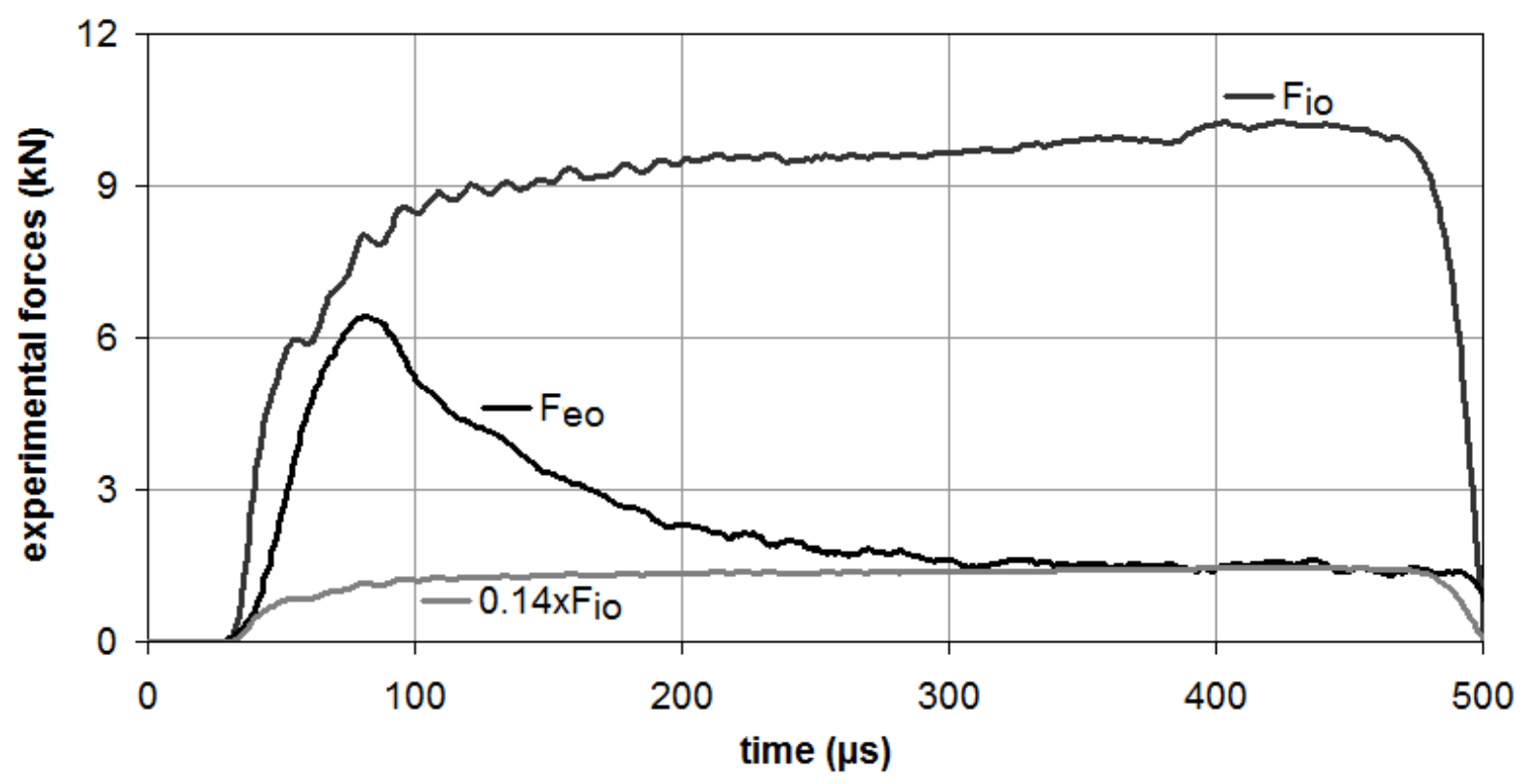

Figure 9: Time evolutions of the external output force $F_{e o}$ and of the internal output force $F_{i o}$

302 deduced from the measured strain waves in the bars and from the Hopkinson formulae.

303

304

The $\frac{F_{e o}}{F_{i o}}$ ratio identified during the stationary phase on Figure 9 in roughly 0.14 . By using relation (17), it leads to $\beta f \approx 0.13$ and if $v \approx 0.4$ to $f \approx 0.05$. 
$310 \quad(18) \quad \tau_{\text {mean }}=\frac{F_{e o}}{2 \pi R L}$

The minimal pressure $p_{\min }$ is reached on $z=0$ and the maximal pressure $p_{\max }$ in

313 reached on $z=L$ (Figure 3). According to relations (5), (8) and (12), $p_{\min }$ and $p_{\max }$ can be

314 expressed from the output forces $F_{e o}$ and $F_{i o}$ :

315

316

(19)

$$
\left\{\begin{array}{l}
p_{\text {min }}=p(0)=\frac{v}{1-v} \frac{F_{i o}}{\pi R^{2}} \\
p_{\text {max }}=p(L)=\frac{v}{1-v} \frac{F_{e o}+F_{i o}}{\pi R^{2}}
\end{array}\right.
$$

$$
p=p_{\text {mean }} \frac{\beta f \exp \left(\frac{\beta f z}{L}\right)}{\exp (\beta f)-1}
$$

324 implies:

(21) $\quad p_{\text {mean }}=\frac{p_{\min }+p_{\max }}{2}$

The mean interface stresses are determined from the experimental output forces $F_{e o}$ and $F_{i o}$, from relations (19) and from relation (21): 


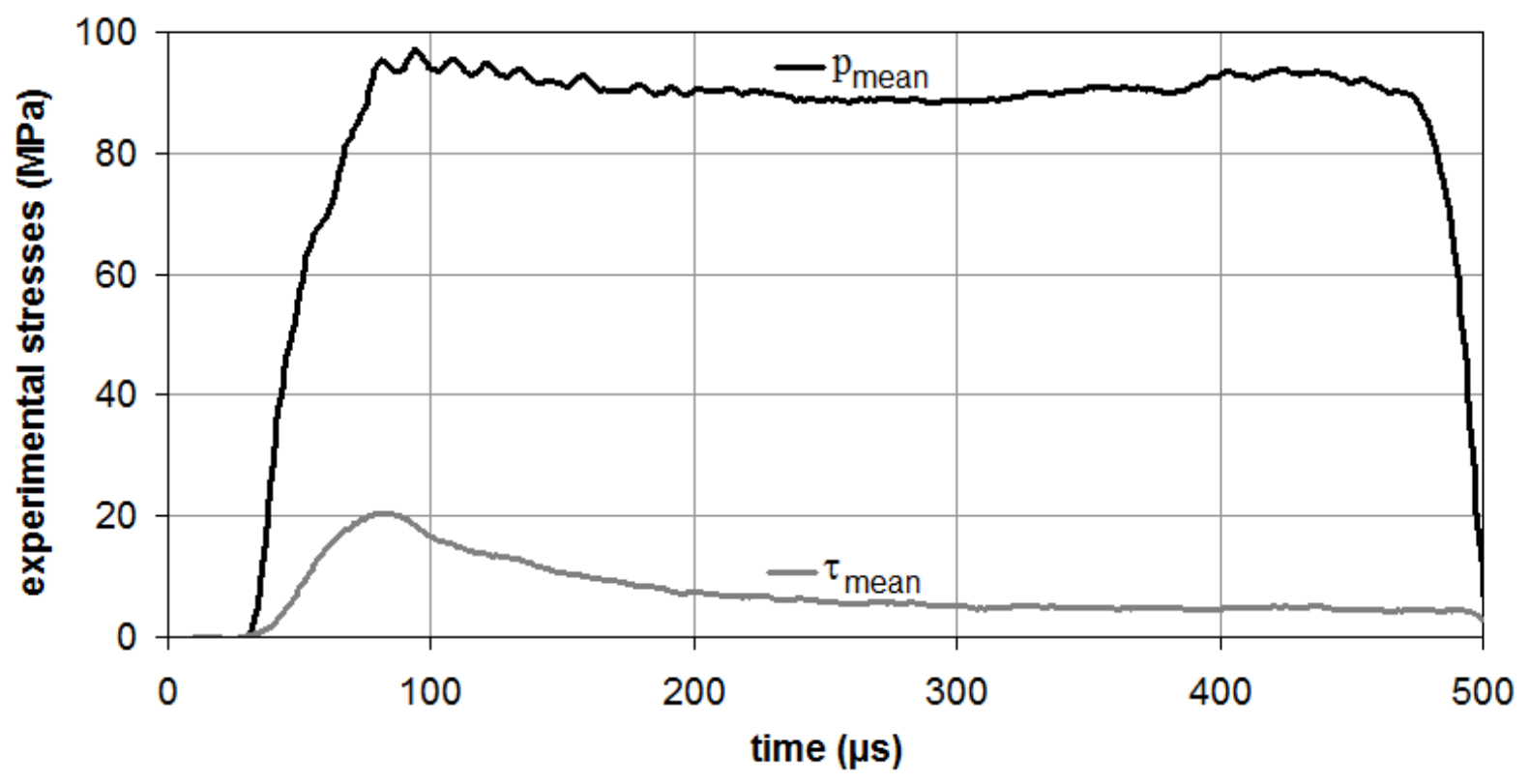

332 Figure 10: Time evolutions of the experimental mean pressure $p_{\text {mean }}$ and of the experimental 333 mean friction stress $\tau_{\text {mean }}$.

Figure 10 shows that the mean pressure $p_{\text {mean }}$ is of the order of 90-100 MPa.

\section{Numerical simulations of the test: check of the results consistency}

Finite element simulations (software: ABAQUS/Explicit) are performed in order to

340 check the consistency of the experimental results and of the friction coefficient magnitude

341 identified from our analytical model $(f \approx 0.05)$. The whole set-up except for the striker is 342 exactly reproduced in these simulations. As Teflon sheets have been inserted between the 343 plug and the sample and between the internal output bar and the sample, these contacts are 344 supposed to be frictionless. The experimental incident strain wave $\varepsilon_{i}$ is used as an imposed 345 loading by applying on the right-hand extremity of the input bar (Figure 1) a pressure equal to 346 the opposite of the measured strain $\varepsilon_{i}$ virtually transported at the extremity multiplied by the 
input bar Young's modulus $E_{i}$. The opposite of $\varepsilon_{i}$ can be seen on Figure 8 . The strains $\varepsilon_{r}, \varepsilon_{t u}$,

$348 \varepsilon_{e t}$ and $\varepsilon_{i t}$ can be considered as the mechanical response of the set-up to $\varepsilon_{i}$ and the simulations

349 have been performed with several values of the friction coefficient $f$ to study its influence on

350 the response.

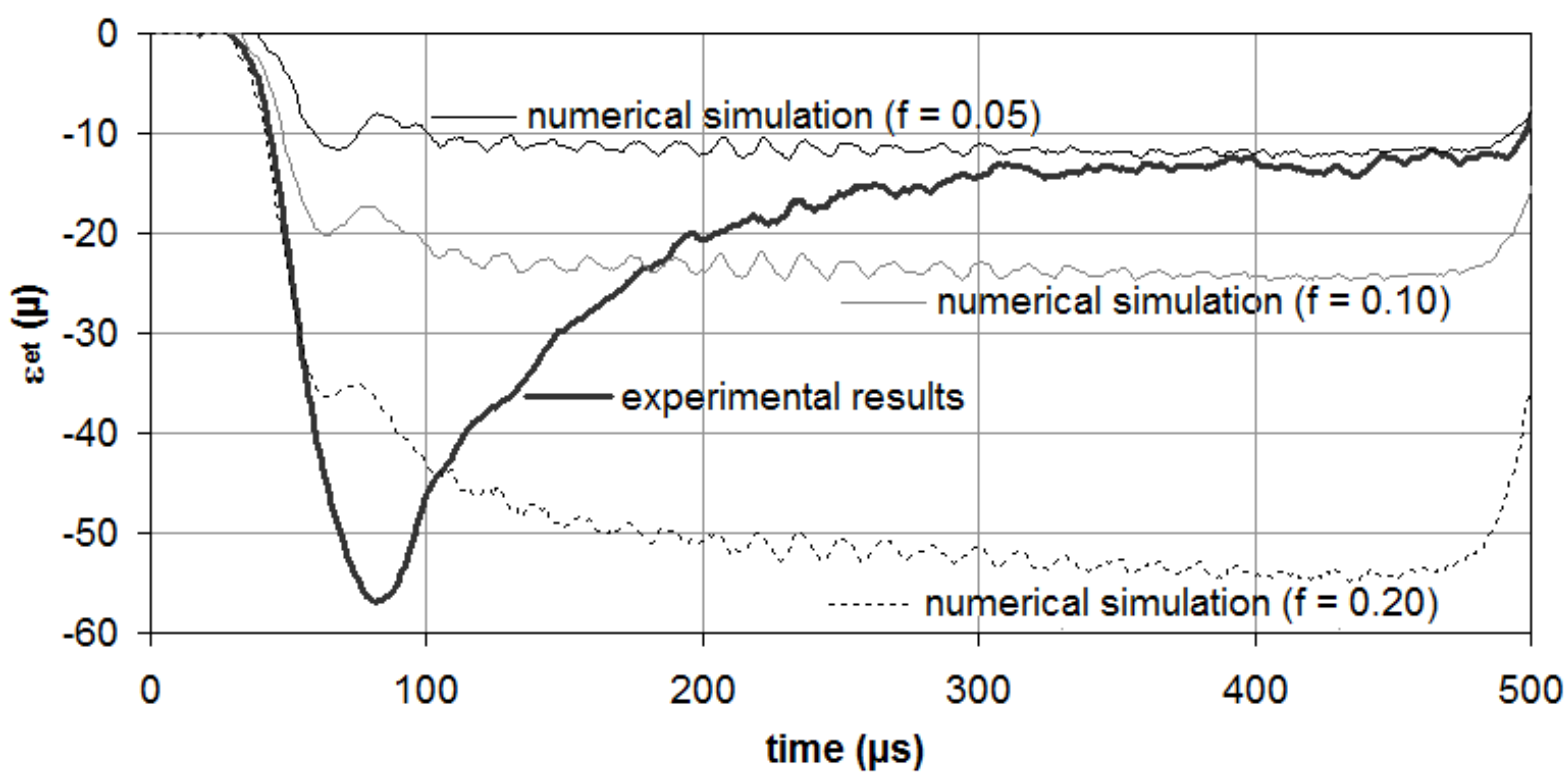

353 Figure 11: Time evolution of the measured external transmitted strain wave $\varepsilon_{e t}$ virtually 354 transported at the external output bar-confinement tube interface and its numerical 355 equivalent depending on the friction coefficient $f$ magnitude. 359 the gauge width. 


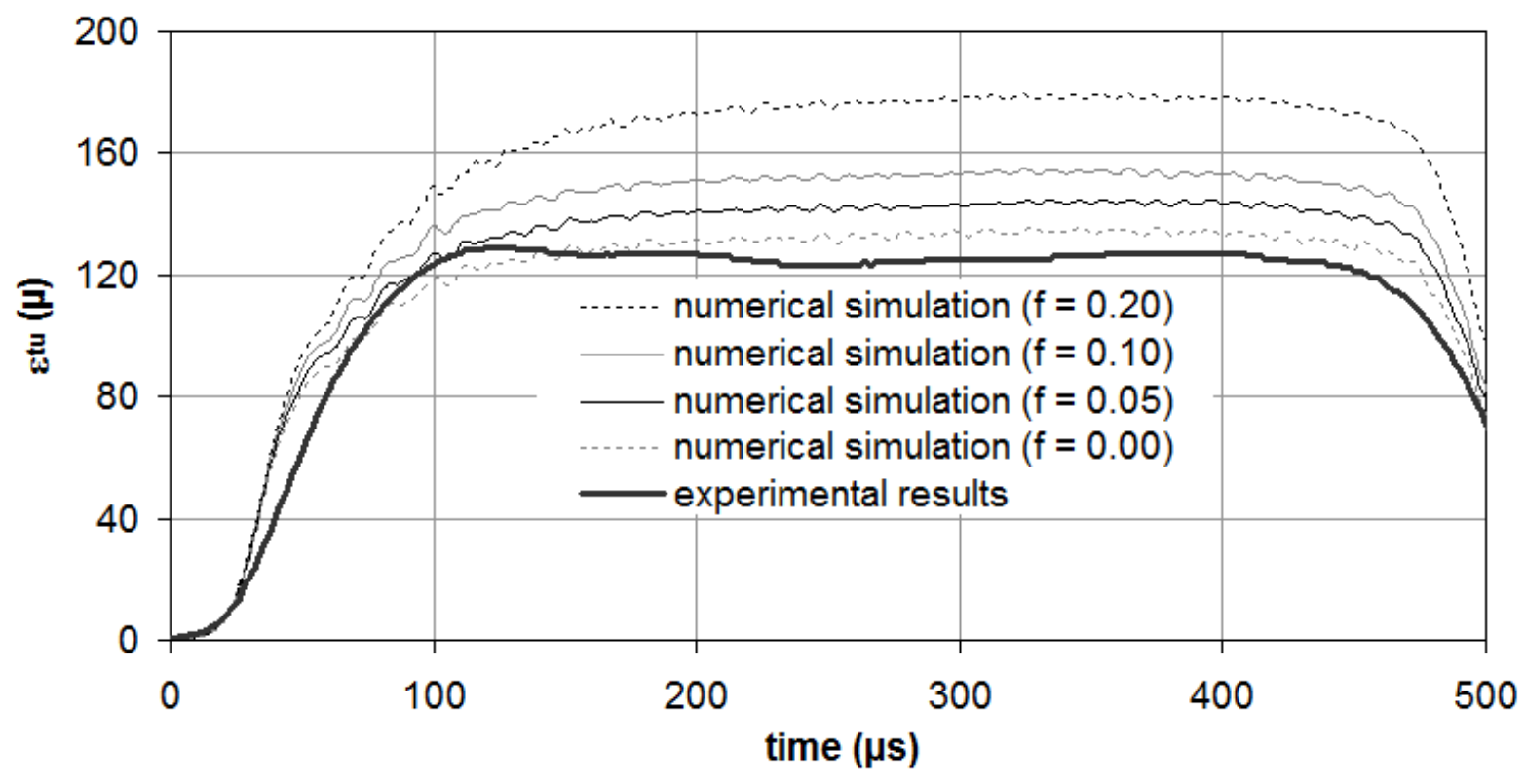

362 Figure 12: Time evolution of the strain measured by the gauge glued on the confinement tube $363 \varepsilon_{t u}$ and its numerical equivalent depending on the friction coefficient $f$ magnitude.

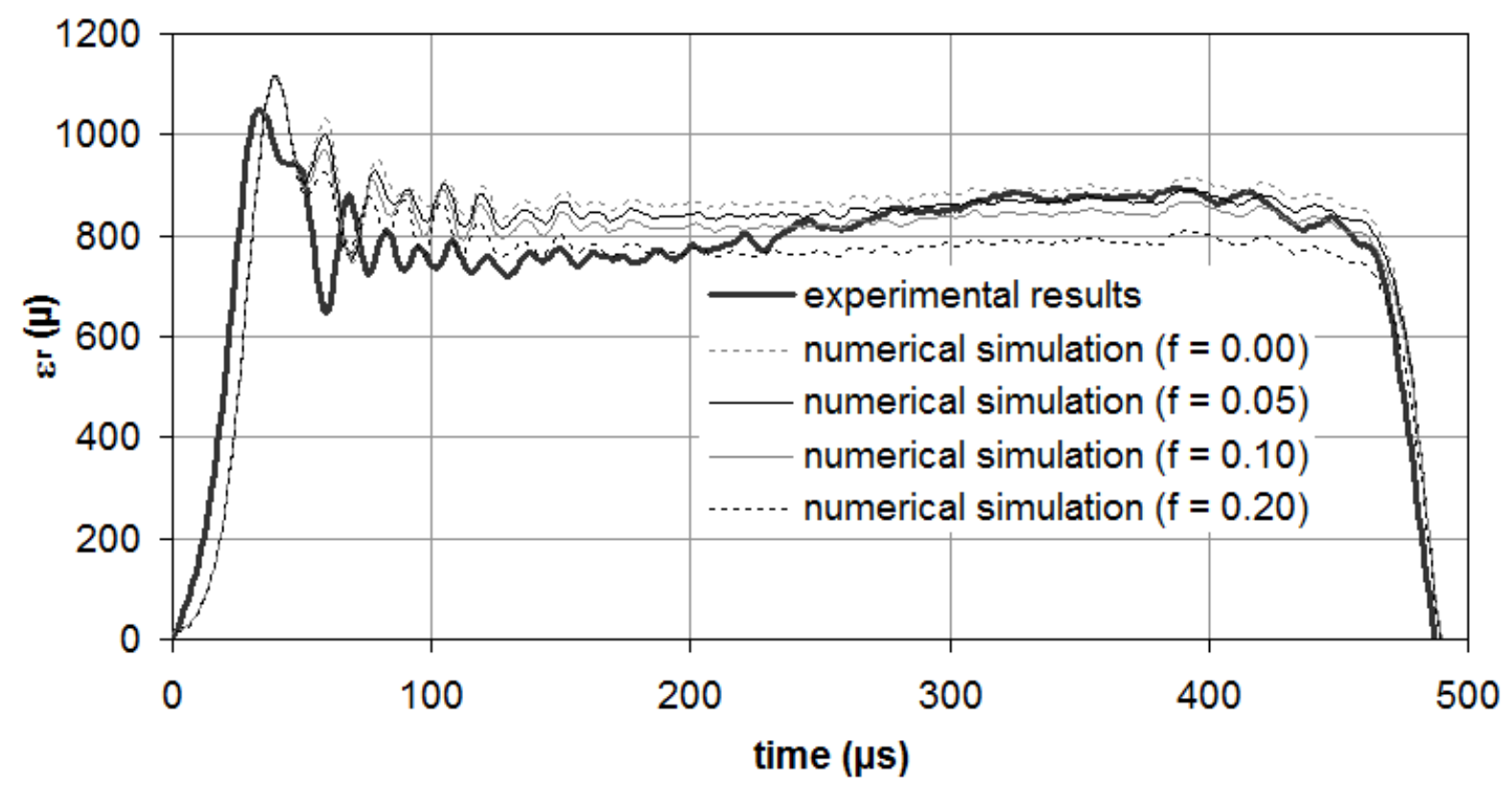

366 Figure 13: Time evolution of the measured reflected strain wave $\varepsilon_{r}$ virtually transported at the 367 input bar - plug interface and its numerical equivalent depending on the friction coefficient $f$ 368 magnitude. 


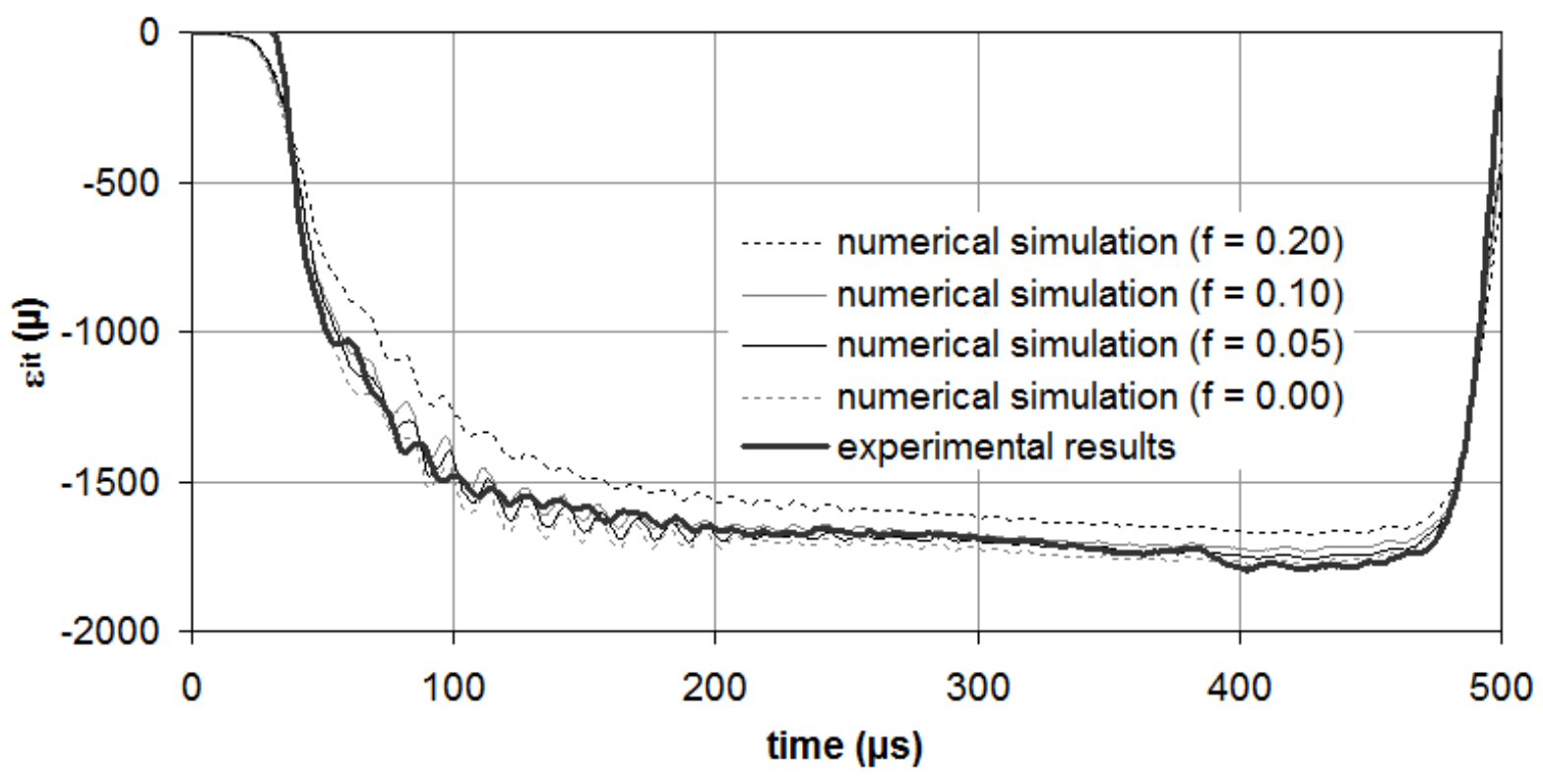

Figure 14: Time evolution of the measured internal transmitted strain wave $\varepsilon_{i t}$ virtually transported at the internal output bar - sample interface and its numerical equivalent depending on the friction coefficient $f$ magnitude.

The external transmitted strain wave $\varepsilon_{e t}$ is proportional to the friction force and is

376 therefore the most friction dependent strain (Figure 11). During the stationary phase, $f=0.05$

377 is a very good fit with the experimental $\varepsilon_{e t}$. The strain measured on the confinement tube $\varepsilon_{t u}$ is 378 also highly dependent on $f$, but a perfect fit cannot be obtained because of the numerical 379 strains high values (Figure 12). The reflected strain wave $\varepsilon_{r}$ and the internal transmitted strain 380 wave $\varepsilon_{i t}$ are quasi-independent on friction (Figure 13 and Figure 14). During the stationary 381 phase, $f=0.05$ is consistent with the measured $\varepsilon_{r}$ and with the measured $\varepsilon_{i t}$. 


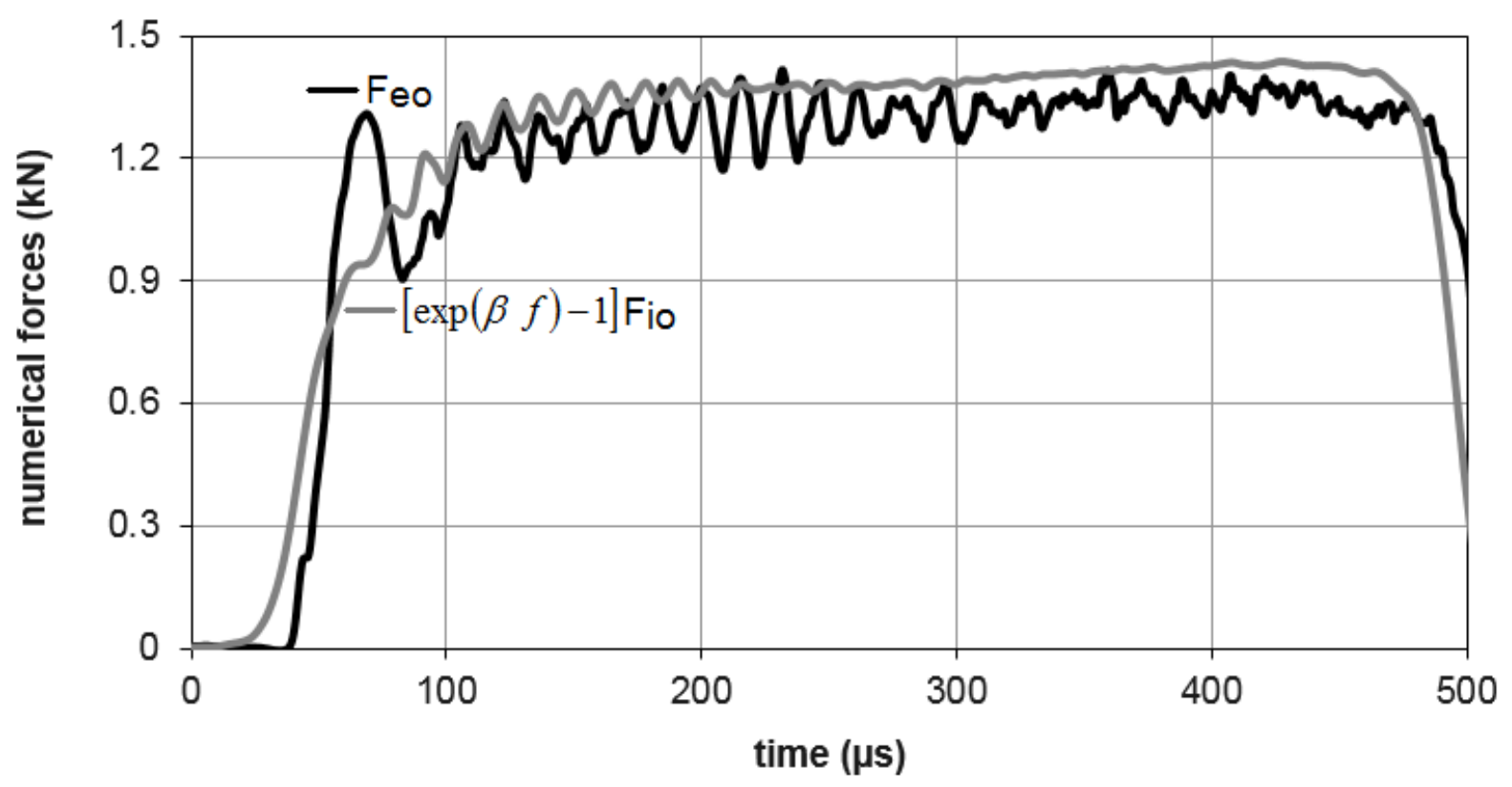

Figure 15: Time evolutions of the numerical external output force $F_{e o}$ and of $391[\exp (\beta f)-1] F_{i o}($ with $f=0.05)$.

Figure 15 shows that the analytical model slightly overestimates the friction force $F_{e o}$.

394 Only this criterion finally matters because $f$ is firstly identified from the $\frac{F_{e o}}{F_{i o}}$ ratio.

\section{Conclusion}

The purpose was to design a set-up enabling the friction measurement between an inert

399 material, mechanically representative of explosives, and a steel confinement. The desired 400 sliding velocities and the desired pressures were respectively $10 \mathrm{~m} / \mathrm{s}$ and $100 \mathrm{MPa}$. A 401 confinement set-up using the split Hopkinson pressure bars technique had to be designed 402 because of the low mechanical resistance of the inert material when submitted to the simple 
403

404

405

406

407

408

409

410

411

412

413

414

415

416

417

418 reviewers for their valuable comments. was launched at only $10 \mathrm{~m} / \mathrm{s}$.

.
compacted material parameters.

compression of classical tribometers. Such a configuration does not enable to make direct measurements. As a result, the stresses and the friction coefficient at the interface between steel and the inert material were identified from indirect measurements, from an analytical model and from the value of the inert material Poisson's ratio. It has been shown that the sliding velocity and the pressure reached roughly $8-9 \mathrm{~m} / \mathrm{s}$ and $90-100 \mathrm{MPa}$ whereas the striker

A very low friction coefficient has been measured: only 0.05. In [20] and [21], a sliding velocity of the order of $1 \mathrm{~mm} / \mathrm{min}$ has been imposed and the corresponding friction coefficient is roughly 0.2 . In [22], the mean pressure is approximately $70 \mathrm{MPa}$ and the sliding velocity is of the order of $2 \mathrm{~m} / \mathrm{s}$. In [20], the mean pressure is approximately $20 \mathrm{MPa}$ and the sliding velocity is around $10 \mathrm{~m} / \mathrm{s}$. In both cases, the friction coefficient is of the order of $0.4-$ 0.5. The reasons of such a variation should be studied in a future work. The friction drop at the very beginning of the test could also be studied by using a time dependent friction model.

The measurements processing could also be improved by using an inverse method like in [23]. Another prospect is the design of a compaction test enabling the friction force measurement. Indeed, the study of the friction in compaction situations is an issue [16], [18] and our device enables the simultaneous determination of the friction parameters and of the

Acknowledgments: The authors would like to thank Maxime Biessy for his help and the 
[1]: Picart D, Delmaire-Sizes F, Gruau C, Trumel H. Ignition of a HMX-based PBX submitted to impact: strain localisation and boundary condition. $16^{\text {th }}$ Conference of the American Physical Society Topical Group on Shock Compression of Condensed Matter (2009).

[2]: Picart D, Bouton E. Non-shock ignition of a HMX-based high explosive: thermomechanical numerical study. $14^{\text {th }}$ International Detonation Symposium, Coeur d'Alène,

[3]: Picart D, Ermisse J, Biessy M, Bouton E, Trumel H. Modelling and simulation of plastic-bonded explosive mechanical initiation. International Journal of Energetic

442 [4]: Field JE, Swallowe GM, Heaven SN. Ignition mechanisms of explosives during mechanical deformations. Proceeding of the Royal Society London A, 383, 231-44 (1982).

445

446 [5]: Gruau C, Picart D, Belmas R, Bouton E, Delmaire-Sizes F, Sabatier J, Trumel H. Ignition of a confined high explosive under low velocity impact. International Journal of Impact Engineering 36, 537-550 (2008). 
450 [6]: Vandersall KS, Chidester SK, Forbes JW, Garcia F, Greenwood DW, Switzer LL and al. Experimental and modelling studies of crush, puncture, and perforation scenarios in the Steven impact test. Office Naval Research 333-05-02, (Eds.), Proceedings of the $12^{\text {th }}$ International Detonation Symposium, San Diego, 131-139 (2002).

[7]: Yodo A and al. Energetic materials for defense - Safety, vulnerability - Friability. AFNOR NF EN 16701 (2014).

[8]: Kim HJ, Emge A, Winter RE, Keightley PT, Kim WK, Falk ML, Rigney DA. Nanostructures generated by explosively driven friction: Experiments and molecular dynamics simulations. Acta Materiala, 57(17), 5270-5282 (2009).

[9]: Rajagopalan S, Irfan MA, Prakash V. Novel experimental techniques for investigating time resolved high speed friction. Wear, 225-229, Part 2, 1222-1237 (1999).

[10]: Huang H, Feng R. Dynamic Friction of SiC Surfaces: A Torsional Kolsky Bar Tribometer Study. Tribology Letters, 27, 329-338 (2007).

[11]: Philippon S, Voyiadjis GZ, Faure L, Lodygowski A, Rusinek A, Chevrier P, Dossou E. A Device Enhancement for the Dry Sliding Friction Coefficient Measurement Between Steel 1080 and VascoMax with Respect to Surface Roughness Changes. Experimental Mechanics, 51(3), 337-358 (2011). 
473 [12]: Dickson PM, Parker GR, Smilowitz LB, Zucker JM, Asay BW. Frictional Heating and 474 Ignition of Energetic Materials. CP845, Conference of the American Physical Society 475 Topical Group on Shock Compression of Condensed Matter, 1057-1060 (2005).

476

477 [13]: Hoffman DM, Chandler JB. Aspect of the tribology of the plastic bonded explosive LX478 04. Propellants, Explosives, Pyrotechnics 29, 368-373 (2004).

479

480

[14]: Bailly P, Delvare F, Vial J, Hanus JL, Biessy M, Picart D. Dynamic behavior of an 482 aggregate material at simultaneous high pressure and strain rate: SHPB triaxial tests. 483 International Journal of Impact Engineering, 38, 73-84 (2011).

[16]: Azhdar B, Stenberg B, Kari L. Determination of dynamic and sliding friction, and observation of stick-slip phenomenon on compacted polymers during high velocity compaction. Polymer Testing, 25, 1069-1080 (2006).

491

492 [17]: Burlion N, Pijaudier-Cabot G, Dahan N. Experimental analysis of compaction of 493 concrete and mortar. International Journal for Numerical and Analytical Methods in Geomechanics, 25(15), 1467-1486 (2001). 
496 [18]: Yong-Ming Tien, Po-Lin Wu, Wei-Hsing Huang, Ming-Feng Kuo, Chen-An Chu. Wall

497 Friction measurement and compaction characteristics of bentonite powders. Powder 498 Technology 173, 140-151 (2007).

499

500 [19]: Janssen HA. Versuche über Getreiedruch in Silozellen. Vereins Z Deutsch Eng 39, 1045

$501 \quad(1895)$.

502

503 [20]: Durand B, Delvare F, Bailly P, Picart D. Friction between steel and a confined inert 504 material representative of explosives under severe loadings. Experimental Mechanics $505 \quad$ DOI 10.1007/s11340-014-9885-z (2014).

506

507 [21]: Durand B, Delvare F, Bailly P, Picart D. Identification of the friction under high 508 pressure between an aggregate material and steel: experimental and modelling aspects. 509 International Journal of Solids and Structures, 50(24), 4108-4117 (2013).

511 [22]: Durand B, Delvare F, Bailly P, Picart D. A friction test between steel and a brittle material at high contact pressures and high sliding velocities. $10^{\text {th }}$ International DYMAT Conference (2012).

514

515 [23]: Durand B, Delvare F, Bailly P. Numerical solution of Cauchy problems in linear 516 elasticity in axisymmetric situations. International Journal of Solids and Structures, 21, 3041-3053 (2011). 